Article

\title{
The Effects of the Barbell Hip Thrust on Post-Activation Performance Enhancement of Change of Direction Speed in College-Aged Men and Women
}

\author{
Ashley J. Orjalo ${ }^{1,+}$, Samuel J. Callaghan ${ }^{2, *,+}$ and Robert G. Lockie ${ }^{1,+}$ D \\ 1 Department of Kinesiology, California State University, Fullerton, Fullerton, CA 92831, USA; \\ ashley.orjalo@csu.fullerton.edu (A.J.O.); rlockie@fullerton.edu (R.G.L.) \\ 2 Faculty of Sport, Applied Health and Performance Sciences (SAHPS), St Mary's University, \\ Twickenham TW1 4SX, UK \\ * Correspondence: samuel.callaghan@stmarys.ac.uk; Tel.: +44-020-8240-4000 \\ + These authors contributed equally to this work.
}

Received: 2 June 2020; Accepted: 19 November 2020; Published: 24 November 2020

\begin{abstract}
This study investigated whether the barbell hip thrust (BHT) enhanced change-of-direction (COD) speed measured by the 505 COD speed test. Forty recreationally trained individuals completed three sessions. Session 1 included one-repetition maximum (1RM) BHT testing to measure absolute and relative strength. Sessions 2 and 3 involved two counter-balanced conditioning activities (CAs): 3 sets $\times 5$ repetitions of the BHT at $85 \% 1 \mathrm{RM}$ and a control condition (CC; 6 min rest). The 505 COD speed test was performed 5 and $2.5 \mathrm{~min}$ pre-CA, and 4,8,12, and $16 \mathrm{~min}$ post-CA in each session. A $2 \times 5$ repeated-measures ANOVA $(p<0.05)$ calculated performance changes across time post-CA. A $2 \times 2$ repeated-measures ANOVA analyzed best potentiated performance. Partial correlations controlling for sex calculated relationships between the 1RM BHT and 505 COD speed test percent potentiation. There was a significant main effect for time $(p<0.001)$, but not for condition $(p=0.271)$ or condition $\times$ time $(p=0.295)$. There were no significant correlations between 1RM BHT and potentiation. The 85\% 1RM BHT did potentiate the 505 4-16 min post-CA but no more than the CC. Nonetheless, a heavy BHT could be programmed prior to COD drills as COD speed could be potentiated and performance improved in men and women.
\end{abstract}

Keywords: agility; college-aged; complex training; hip extension; lower-body strength

\section{Introduction}

Agility is an essential quality of many athletes and has been defined as an action that features an initiation of body movement, change-of-direction (COD), or rapid acceleration or deceleration in response to a stimulus [1]. In addition to the cognitive component, the physical component of agility is termed COD speed. COD speed involves factors such as the athlete's sprint technique, strength, and power [1]. Explosive and decisive COD movements are undertaken within the match-play of many individual and team-based sports and are often central to success. For example, a line break in rugby league, attempting a catch in cricket or a fast break in basketball. Accordingly, different training methods have been used to improve COD speed. This includes sprint training, plyometrics, specific COD drills, the flywheel paradigm, and resistance training [2-5]. One training method for acute changes in COD speed that has received limited analysis involves post-activation performance enhancement (PAPE), particularly for field- or court-based sports.

PAPE is where a muscle's contractile history contributes to enhanced power-based actions [6]. Specifically, changes in muscle temperature, muscle/cellular water content, and muscle activation have been suggested to partially explain the effect of increased force production and enhanced power-based 
actions [7]. This is typically achieved through complex training, which involves a superset combining a strength exercise (or a high force output exercise such as plyometrics) immediately followed by a power-based exercise (e.g., a jump or sprint) [8]. The first exercise in the complex pair is often referred to as a conditioning activity (CA). There has been some analysis of PAPE and COD speed [9-11]. Although not a true representation of COD speed, Okuno et al. [9] investigated whether a CA of back squats ( 1 set $\times 5$ repetitions at $50 \%$ one-repetition maximum (1RM), 1 set $\times 3$ repetitions at $70 \%$ $1 \mathrm{RM}$, and 5 sets $\times 1$ repetition at $90 \% 1 \mathrm{RM})$ could enhance repeated-sprint ability test $(6 \times 30 \mathrm{~m}$ sprints with a $180^{\circ} \mathrm{COD}$ at $15 \mathrm{~m}$ ) in male handball players. The results suggested that the best and mean times from the six sprints were faster following the CA. Sole et al. [10] also analyzed the use of the back squat as a CA for a 10 meter $(\mathrm{m})$ shuttle run test, which required participants to perform short, maximal sprints interspersed by two $180^{\circ}$ change of directions, in collegiate male and female athletes. Although there was a not a significant decrease in shuttle run times 4,8 , and 12 min post-CA, Sole et al. [10] noted that due to individual responses, there was potential application of PAPE for COD speed. Orjalo et al. [11] analyzed whether 3 sets $\times 5$ repetitions of lateral bounds (unweighted and performed with an additional load of $10 \%$ body mass) could enhance COD speed as measured by the 505 COD speed test. The results suggested that the overload provided by lateral bounds was not sufficient to potentiate 505 COD speed test time. One of the recommendations from Orjalo et al. [11] was to analyze whether heavy-resistance exercises were more appropriate to induce a PAPE effect on COD speed.

The overload provided by the CA, in addition to the biomechanical specificity between the $\mathrm{CA}$ and power-based exercise, is an important factor in determining whether PAPE occurs [6,12]. For example, one reason why Sole et al. [10] may not have found significant changes to shuttle times following the back squat is that the back squat emphasizes vertical force production [13]. Whereby, sprint acceleration, which is a component of COD speed [1], places a greater emphasis on horizontal force [14]. An exercise that may target the muscles responsible for horizontal force production in sprinting is the barbell hip thrust (BHT). The hip extensors (i.e., the gluteals) are the prime movers of the body during the stance phase of sprinting [15]. When compared to a 10RM back squat, the 10RM BHT led to greater gluteus maximus and biceps femoris activation [16]. There is some evidence as to the benefits of using the BHT to potentiate linear sprint performance $[17,18]$. The BHT performed with 3 sets of 6 repetitions at 85\% 1RM enhanced 10- and $15 \mathrm{~m}$ sprint times in handball players [17], and 5, 10, and $20 \mathrm{~m}$ sprint times in soccer players [18], 4 and $8 \mathrm{~min}$ post-CA. Due to the importance of acceleration to COD speed [1], it would be worth investigating whether the $85 \%$ 1RM BHT could potentiate COD speed as measured by a task such as the 505 COD speed test.

Training history can also influence whether an individual experiences PAPE [12,18-20]. Stronger individuals can potentiate sooner following a strength intervention [20,21], and greater peak force and power production during a resistance exercise could positively influence sprint PAPE [22]. However, the extent to which training history influences COD speed performance among field- and court-based athletes has not been appropriately investigated. There was a relationship between a greater 1RM BHT with larger 15 [17] and $20 \mathrm{~m} \mathrm{[18]} \mathrm{sprint} \mathrm{potentiation} \mathrm{in} \mathrm{handball} \mathrm{and}$ soccer players, respectively. In addition to determining whether the BHT can enhance COD speed measured by the 505 COD test, it is important to document whether greater absolute and relative BHT strength can influence the timing and degree of PAPE specific to the 505 COD speed test among fieldand court-based athletes.

Therefore, the purpose of this research was to determine whether 3 sets of 5 repetitions at $85 \%$ $1 \mathrm{RM}$ of the BHT could potentiate COD speed measured by the 505 COD speed test in college-aged men and women. It was hypothesized that the BHT would lead to a faster 505 performance compared to a control condition (CC) of 6 min rest. Lastly, it was hypothesized that there would be significant relationships between absolute and relative BHT load and percent potentiation in the 505 COD speed test $[17,18]$. 


\section{Materials and Methods}

\subsection{Subjects}

A convenience sample of 40 subjects $(23.28 \pm 2.82$ years; $1.70 \pm 0.09 \mathrm{~m} ; 73.00 \pm 12.95 \mathrm{~kg})$ were recruited for this study, including 20 males $(23.95 \pm 3.24$ years; $1.77 \pm 0.06 \mathrm{~m}$; body mass: $80.46 \pm 12.15 \mathrm{~kg})$ and 20 females $(22.60 \pm 2.21$ years; height: $1.63 \pm 0.06 \mathrm{~m}$; body mass: $65.54 \pm 8.92 \mathrm{~kg})$. Similar to Orjalo et al. [11], G*Power software (v 3.1.9.3, Universität Kiel, Düsseldorf, Germany) confirmed post hoc that 40 subjects within a $2 \times 5$ repeated-measures analysis of variance (ANOVA,) indicated data could be interpreted with an effect level of 0.2 and power level of 0.9 , when significance was set at 0.05 [23]. Furthermore, 40 subjects for the $2 \times 2$ repeated-measures ANOVA allowed data to be interpreted with an effect level of 0.25 and power level of 0.8 , when significance was set at 0.05 [23]. Lastly, G*Power software confirmed that for a correlation, point biserial model, a sample size of 40 allowed data to be interpreted with an effect level of 0.4 when the power level was 0.8 and significance was set at 0.05 [23]. Subjects were recruited if they satisfied the following conditions: were college-aged (18-30 years); had a training history which included a resistance training age of at least one year (minimum of $3 \mathrm{~h}$ per week) [11,18-20], and were experienced with the movements of the BHT; were recreationally involved in a field or court sport (i.e., tennis, soccer, lacrosse, flag football, ultimate Frisbee, basketball, badminton, and volleyball), at least twice a week for the past two years; and were free from any lower-extremity injuries that could influence study participation [11]. No minimum relative strength for the BHT exercise was required for participation in the study. The university's institutional review board (HSR-18-19-229) approved this study. The requirements of the study, inclusive of the risks and benefits associated with participation were provided to all subjects. Written informed consent was obtained from subjects prior to testing.

\subsection{Procedures}

Testing was conducted over three days with $48-72 \mathrm{~h}$ separating each session. Each subject completed the testing sessions at the same time of day, dependent upon their availability $[11,22,24,25]$. The first testing session initially required 1RM BHT testing and 505 COD speed test familiarization. The subsequent two testing sessions were completed in a counter-balanced order utilizing two different CAs ( 3 sets $\times 5$ repetitions of BHT with $85 \% 1 R M$, and a CC of 6 min rest). Hence, half the sample performed the BHT first, and half performed the CC first, and then switched for the final testing session. Subjects were instructed to refrain from any intensive exercise or any form of stimulant and asked to maintain their typical dietary intake in the $24 \mathrm{~h}$ period prior to testing.

During session one, the subject's age, height, and body mass were taken. A stadiometer (Detecto, Webb City, MO, USA) was used to measure height, while electronic scales (Ohaus, Parsippany, NJ, USA) were used to measure the body mass of each subject. All subjects completed the same warm-up, which consisted of $5 \mathrm{~min}$ of jogging at a self-selected pace on a treadmill, followed by $10 \mathrm{~min}$ of dynamic stretching. Following this, subjects performed two trials of the 505 COD test to familiarize themselves for the next two sessions (all 505 COD speed trials were completed on the same indoor, wooden sprung basketball court). Once the $505 \mathrm{COD}$ performances were completed, they performed the 1RM BHT test in an indoor weight room. During sessions 2 and 3, the subjects completed the same standardized dynamic warm-up as previously outlined, then at 5 and $2.5 \mathrm{~min}$ prior to the CA performed two trials of the 505 COD test (one per leg). The order of the trials was determined by the subject's dominant leg (i.e., their preferred cutting leg) [26]. The testing order with regard to the turning leg was kept consistent for each subject across all trials. After baseline measurements, one of the two CAs (BHT or CC) was completed by the subject, before they completed the 505 COD test at 4 , 8,12 , and 16 min post-CA [11,17,18,22,24,25,27-29]. Subjects wore their own athletic footwear for each testing session, and this same footwear was worn for all testing sessions. 


\subsection{Barbell Hip Thrust (BHT)}

During session one, subjects performed a 1RM BHT to measure absolute and relative strength, and to determine the weight that was used for the 85\% 1RM PAPE condition. To perform the BHT, subjects were instructed to start by sitting on the ground with their legs flat on the floor, feet shoulder-width apart, and their upper back against a padded exercise bench. A standard Olympic barbell and weight plates (Diamond Pro, Decatur, AL, USA), with a pad positioned on the bar for comfort [30], was placed above their lower legs, slightly below the knees. Once the subject positioned the barbell above their pelvis, they then assumed the start position of the exercise by bringing their heels toward the bench by flexing the knees (Figure 1A). Subjects then lifted their hips until their knee joint created a $90^{\circ}$ angle with a vertical tibia (this was visually assessed by the researcher; Figure 1B). They held this position for one second before lowering the barbell in a controlled manner [30].

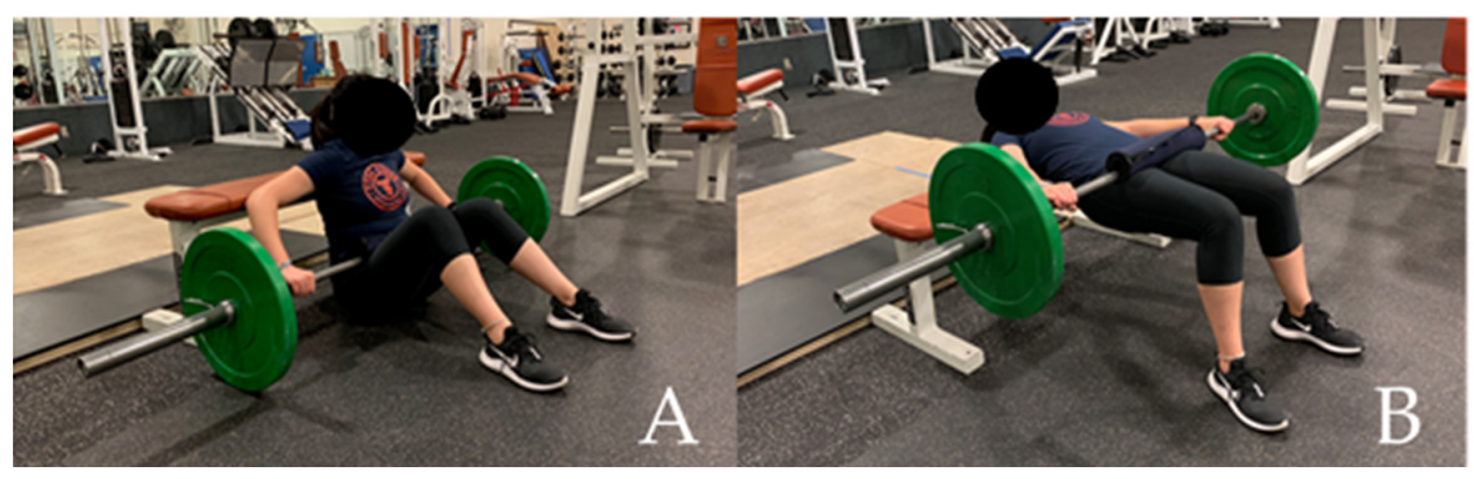

Figure 1. Starting (A) and vertical (B) position of the barbell hip thrust (BHT).

The procedures for finding the 1RM BHT were as follows. After the standard dynamic warm-up, the BHT warm-up sets completed by the subject consisted of 3 sets $\times 8$ repetitions at $30 \%, 40 \%$, and $50 \%$ of the subject's perceived 1RM, with 2 min of rest provided between sets [17]. Once the warm-up sets were completed, a load equivalent to $\sim 90-95 \%$ of the subject's perceived 1RM was placed on the bar, and the subject complete a single repetition. After this, the weight was increased by approximately $5 \%$ and subjects completed single repetitions until the $1 \mathrm{RM}$ was attained, with $3 \mathrm{~min}$ rest provided between attempts [31,32]. In order for the repetition to be counted, the BHT had to be completed with good form (i.e., the knee joint had to reach a $90^{\circ}$ angle with a vertical tibia), which was visually assessed by the researcher [17]. The 1RM was attained within 5 attempts. Verbal encouragement was provided to all subjects for each 1RM attempt. Absolute strength was taken as the 1RM load lifted; the $1 \mathrm{RM}$ was also scaled relative to body mass [31,32].

\subsection{Change-of-Direction Speed Test}

The 505 COD speed test incorporates two $5 \mathrm{~m}$ sprints separated by a $180^{\circ}$ turn (Figure 2). The protocol utilized within the current study is identical to that of previous research $[11,26,33-39]$. The subject began at the start line and accelerated through the timing gate (Brower Timing Systems, Draper, UT, USA) to the turning line, which was indicated by a line marked on the ground. The subject placed either their dominant or non-dominant foot, depending on the trial, on or behind the turning line, executed a $180^{\circ}$ turn before sprinting back through the gate. If the subject failed to place part of their foot on or behind the turning line or turned off the incorrect foot, the trail was disregarded and reattempted after the required rest interval. The timing gates recorded the time to the nearest 0.01 second (s). The mean of the trials completed at each time point was used for analysis. At baseline however, the mean of the four trials (i.e., two trials at $5 \mathrm{~min}$ and two trials at $2.5 \mathrm{~min}$ pre-CA) was used for analysis [11,22,24,25,27-29]. At each time point, the dominant leg was tested first [11,26]. 


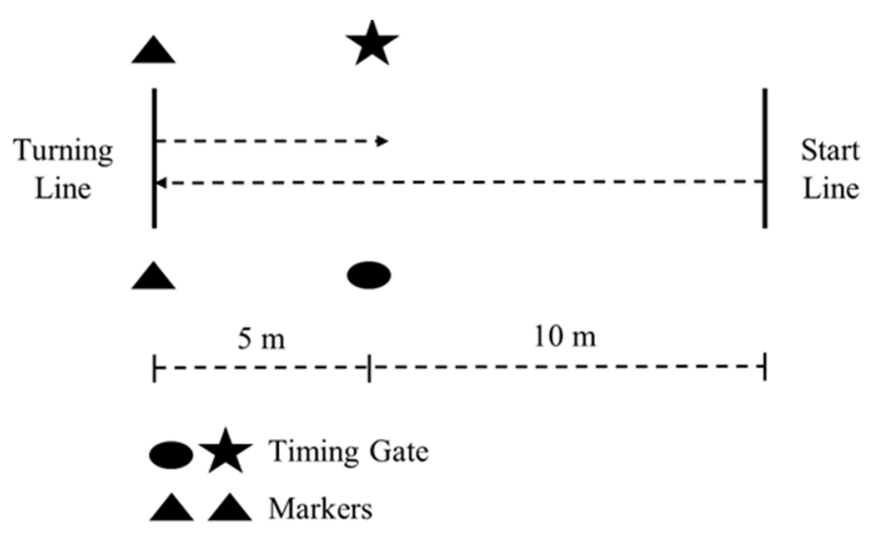

Figure 2. Structure of the 505 change-of-direction (COD) speed test.

\subsection{Post-Activation Performance Enhancement Interventions}

As stated, following the dynamic warm-up, subjects performed two trials of the 505 COD speed test at 5 and $2.5 \mathrm{~min}$ prior to the CA with the mean of all CAs calculated to provide baseline data $[11,22,24,25,27-29]$. After recording the baseline data, subjects walked $\sim 30 \mathrm{~m}$ to an indoor gym and performed one of two CAs. One session involved 3 sets $\times 5$ repetitions of the BHT with $85 \%$ $1 \mathrm{RM}$, with a $2 \mathrm{~min}$ rest between sets $[17,18]$. The concentric phase for each BHT repetition was to be performed as forcefully and rapidly as possible, while the bar was to be lowered with control in the eccentric phase [40]. For the CC, subjects were seated for $6 \mathrm{~min}$, which was the approximate duration for the BHT CA $[22,24,25]$. After the CA, subjects walked $\sim 30 \mathrm{~m}$ to the basketball court where the 505 COD speed test was performed and completed, with two trials at each of the following time points: $4,8,12$, and $16 \mathrm{~min}$ post-CA [11,22,24,25,27-29]. The $4 \mathrm{~min}$ time was used as the start point as this was the initial time used in previous BHT PAPE research $[17,18]$. Subjects were not informed as to what their preceding 505 COD speed test times were to eliminate the influence of feedback $[11,22]$. The mean of the two trials performed at each time point was used for analysis.

The following equation was utilized to calculate Post-CA COD performance percentage change: $\%$ Potentiation $=$ Potentiated Variable $(\mathrm{COD}$ at $4,8,12$, and $16 \mathrm{~min}) \div$ Unpotentiated Variable (average baseline) $\times 100$. To interpret the Post-CA performance percentage change; a value less than 100 indicated a faster 505 COD speed performance (i.e., positive potentiation); a value greater than 100 indicated a slower 505 COD speed performance (i.e., negative potentiation); and a value equal to 100 indicated no change in 505 COD speed performance (i.e., no potentiation) $[11,19,22,24,25]$.

\subsection{Statistical Analysis}

All analyses were determined via the Statistics Package for Social Sciences (Version 26.0; IBM Corporation, New York, NY, USA). Descriptive statistics (mean \pm standard deviation (SD)) were calculated for all subjects. Q-Q plot analysis was utilized to determine the normality of the data $[11,41,42]$. Intraclass correlation coefficient (ICC) and coefficient of variation (CV) were determined to assess the reliability of the data. The criterion for reliability was set at ICC $\geq 0.70$ and CV $<10 \%[43,44]$. As both men and women can experience PAPE [12], the sexes were combined. This approach of combining the sexes with regard to PAPE has been utilized in previous research $[10,11,25]$. The statistical analysis performed was similar to that for Orjalo et al. [11]. To measure within-subject 505 COD speed performance across the assessed time points, a $2 \times 5$ repeated-measures ANOVA (condition (BHT and CC) $\times$ time (baseline, 4, 8, 12, and $16 \mathrm{~min}$ )) was used. A similar approach has been used in previous research $[22,25,28,45]$. To analyze the individual responses of each subject, regardless of the time point it occurred post-CA, best potentiated performance was analyzed $[22,25,46]$. A 2 (BHT and CC) $\times 2$ (baseline and best 505) repeated-measures ANOVA was used for this analysis. If a significant $F$ ratio was detected in any ANOVA calculations, post hoc pairwise tests were conducted using the Bonferroni 
adjustment procedure for multiple comparisons. The individual results of all participants were also described to allow for a more detailed examination of the effects of PAPE via the BHT upon COD speed, which may provide pertinent information to the strength and conditioning practitioner not possible via grouped analysis.

To investigate relationships between absolute and relative strength measured by the 1RM BHT with percent 505 potentiation, partial correlations were used. Due to the established differences between women and men with regard to strength, power, and speed tests, partial correlations controlling for sex were utilized [37,47,48]. Similar to the clarifications stated by Orjalo et al. [11] and Dillman, Carpentier, and Stevens [49], sex was coded (males $=1$; females $=2$ ) to allow the partial correlation analysis to be conducted. The approach of utilizing partial correlations to control for the confounding effects of sex, so as to investigate the relationship between different fitness $[11,37,50-52]$ and other variables $[49,53,54]$ has been undertaken numerous times in previously published studies. The correlation strength was designated as follows: an $r$ between 0 to \pm 0.3 was small; \pm 0.31 to \pm 0.49 , moderate; \pm 0.5 to \pm 0.69 , large; \pm 0.7 to \pm 0.89 , very large; and \pm 0.9 to \pm 1 , near perfect, for relationship prediction [55]. For all analyses, significance was set at $p<0.05$.

\section{Results}

The Q-Q plot analysis determined that all assessed variables were normally distributed. All assessed variables demonstrated acceptable levels of reliability (ICC $\geq 0.70$ and CV $<10 \%$ ). Table 1 displays the descriptive data for the 505 COD speed test following each condition (i.e., BHT and CC). The percent potentiation is displayed in Table 2. When considering the 505 data recorded from 4 to $16 \mathrm{~min}$ post-CA relative to baseline, there was no significant main effect for condition $\left(\mathrm{F}_{1,39}=3.402\right.$, $p=0.073$, partial $\left.\eta^{2}=0.183\right)$ or condition $\times$ time $\left(\mathrm{F}_{4,36}=3.402, p=0.170\right.$, partial $\left.\eta^{2}=0.041\right)$. There was a significant main effect for time $\left(\mathrm{F}_{4,36}=9.517, p<0.001\right.$, partial $\left.\eta^{2}=0.196\right)$. Post hoc analyses indicated that the pooled 505 data at $4 \mathrm{~min}(p=0.005), 8 \mathrm{~min}(p=0.014), 12 \mathrm{~min}(p=0.005)$, and $16 \mathrm{~min}(p=0.001)$ were all significantly faster than at baseline. Regarding the best potentiated 505 time, there was again no significant main effect for condition $\left(\mathrm{F}_{1,39}=1.249, p=0.271\right.$, partial $\left.\eta^{2}=0.031\right)$ or condition $\times$ time $\left(\mathrm{F}_{4,39}=1.125, p=0.295\right.$, partial $\left.\eta^{2}=0.028\right)$. There was a significant main effect for time $\left(\mathrm{F}_{1,39}=67.651\right.$, $p<0.001$, partial $\left.\eta^{2}=0.634\right)$, with the best potentiated 505 time significantly $(p<0.001)$ faster than the baseline. The individual results of each subject across each condition and time point are presented in Figure 3.

Table 1. Descriptive statistics (mean \pm standard deviation (SD)) for the 505 change-of-direction speed test following the post-activation performance enhancement interventions (barbell hip thrust (BHT) and control condition (CC)).

\begin{tabular}{ccc}
\hline Data Collection Time Points & BHT (s) & CC (s) \\
\hline Baseline & $2.82 \pm 0.27$ & $2.84 \pm 0.28$ \\
4 min & $2.76 \pm 0.25$ & $2.82 \pm 0.26$ \\
8 min & $2.77 \pm 0.26$ & $2.81 \pm 0.27$ \\
12 min & $2.77 \pm 0.26$ & $2.80 \pm 0.28$ \\
16 min & $2.74 \pm 0.25$ & $2.79 \pm 0.30$ \\
Best & $2.70 \pm 0.25$ & $2.74 \pm 0.27$ \\
\hline
\end{tabular}

Table 2. Percent potentiation (\%) compared to baseline across all time points post-barbell hip thrust (BHT) and control condition (CC).

\begin{tabular}{ccc}
\hline Data Collection Time Points & BHT & CC \\
\hline 4 min & $97.18 \pm 4.04$ & $99.47 \pm 3.17$ \\
8 min & $98.26 \pm 3.02$ & $99.30 \pm 3.62$ \\
12 min & $98.21 \pm 3.48$ & $98.76 \pm 3.95$ \\
16 min & $97.22 \pm 3.46$ & $98.27 \pm 4.54$ \\
Best & $95.97 \pm 3.19$ & $96.72 \pm 3.82$ \\
\hline
\end{tabular}




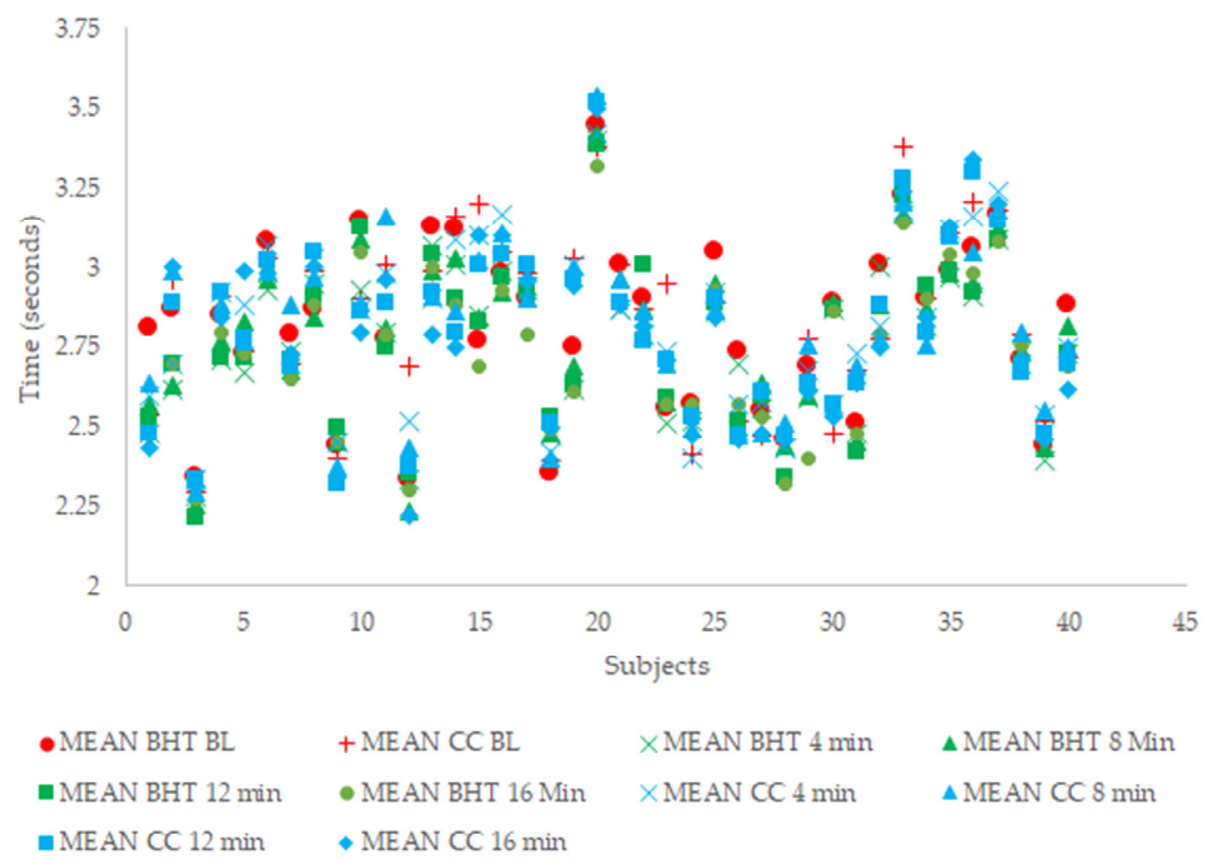

Figure 3. The mean, individual 505 change-of-direction speed test results across each condition and time-point. $\mathrm{BHT}=$ barbell hip thrust; $\mathrm{CC}=$ control condition; $\mathrm{BL}=$ baseline; $\mathrm{min}=$ minutes.

The mean 1RM BHT (absolute strength) for the subjects in this study was $156.26 \pm 64.17 \mathrm{~kg}$ $($ males $=198.68 \pm 55.87 \mathrm{~kg}$; females $=113.83 \pm 39.27 \mathrm{~kg})$. Accordingly, the mean relative strength measure equaled $1.44 \pm 0.24 \mathrm{~kg} \cdot \mathrm{BM}^{-1}\left(\right.$ males $=2.50 \pm 0.81 \mathrm{~kg} \cdot \mathrm{BM}^{-1}$; females $\left.=1.76 \pm 0.62 \mathrm{~kg} \cdot \mathrm{BM}^{-1}\right)$. Table 3 displays the correlation data for absolute and relative strength and the percent potentiation for BHT and CC. There were no significant correlations between the lower-body strength measures and 505 percent potentiation for either of the CAs.

Table 3. Correlation data between absolute (barbell hip thrust (BHT) one-repetition maximum (1RM) load) and relative (BHT 1RM load relative to body mass) strength and percent potentiation in the 505 following the post-activation performance enhancement conditions (BHT or control condition (CC)).

\begin{tabular}{ccccc}
\hline \multirow{2}{*}{ Condition } & \multicolumn{2}{c}{ Absolute Strength } & \multicolumn{2}{c}{ Relative Strength } \\
\cline { 2 - 5 } & $\boldsymbol{r}$ & $\boldsymbol{p}$ & $\boldsymbol{r}$ & $\boldsymbol{p}$ \\
\hline BHT & & & & \\
$4 \mathrm{~min}$ & 0.151 & 0.357 & 0.115 & 0.484 \\
$8 \mathrm{~min}$ & 0.064 & 0.698 & 0.105 & 0.523 \\
$12 \mathrm{~min}$ & 0.186 & 0.256 & 0.112 & 0.496 \\
$16 \mathrm{~min}$ & -0.027 & 0.872 & 0.009 & 0.956 \\
Best & 0.080 & 0.630 & 0.060 & 0.718 \\
CC & & & & \\
$4 \mathrm{~min}$ & 0.009 & 0.955 & 0.001 & 0.996 \\
$8 \mathrm{~min}$ & 0.209 & 0.202 & 0.208 & 0.203 \\
$12 \mathrm{~min}$ & 0.006 & 0.969 & -0.011 & 0.945 \\
$16 \mathrm{~min}$ & 0.020 & 0.906 & 0.044 & 0.790 \\
Best & 0.020 & 0.906 & 0.002 & 0.991 \\
\hline
\end{tabular}

\section{Discussion}

The purpose of this study was to determine whether 3 sets $\times 5$ repetitions of BHT with $85 \% 1$ RM could potentiate COD performance as measured by the 505 COD speed test in college-aged men and women. Previous research has shown the benefit of this exercise and load for enhancing linear sprint 
performance $[17,18]$. The results provided some support to the hypothesis, as 505 COD speed test performance was acutely enhanced at every time point analyzed in this study. However, any acute improvements to the $505 \mathrm{COD}$ test time that resulted from the use of the BHT as a CA were no different from a CC of 6 min rest. Further, and counter to other PAPE studies $[12,17,18,20]$, the partial correlation data indicated no significant relationships between absolute and relative strength measured by the BHT and 505 percent potentiation. As will be discussed, these results were likely influenced by the training history of the subjects in this study who all had a minimum training age of one year. However, they were not high-level athletes with a training history consistent with elite sport. Nonetheless, the data presented could have practical application for strength and conditioning coaches. The BHT could be used as a CA with COD drills, as even though any enhancements were not different to a CC, a faster 505 COD test did result after the BHT. Consequently, this has implications for training efficiency in college-aged men and women, as strength and conditioning coaches can prescribe the BHT prior to COD drills, without a decrease in performance, while allowing training adaptations to still occur.

Previous research has shown that 3 sets $\times 5$ repetitions of BHT with $85 \% 1 \mathrm{RM}$ can enhance sprinting speed over $15 \mathrm{~m}$ in male handball players [17] and over $20 \mathrm{~m}$ in male soccer players [18]. Interestingly, irrespective of the PAPE condition, 505 COD speed test times were faster at all time points relative to baseline. This also meant the best potentiated time following the BHT or CC was also faster than the baseline. These results may have occurred due to the training history of the subjects. The baseline 505 COD test times of the current subjects (BHT baseline $=2.82 \pm 0.27 \mathrm{~s} ; \mathrm{CC}$ baseline $=$ $2.84 \pm 0.28 \mathrm{~s}$ ) were relatively slower compared to those of higher-level athletes. For example, in elite rugby league players, Delaney et al. [33] found 505 COD test times of $2.21 \pm 0.07 \mathrm{~s}$ and $2.23 \pm 0.08 \mathrm{~s}$ for the dominant and non-dominant legs, respectively. Lockie et al. [39] found $505 \mathrm{COD}$ test times of $2.24 \pm 0.14 \mathrm{~s}$ and $2.20 \pm 0.09 \mathrm{~s}$ for the left and right legs, respectively, in Division I collegiate men's soccer players. Division I and II women's soccer players had mean 505 COD test times of $2.40 \pm 0.10 \mathrm{~s}$ and $2.60 \pm 0.11 \mathrm{~s}$, respectively [38]. The subjects from this study were clearly slower than elite and collegiate athletes, so potentially, they had a greater ceiling to improve with any form of stimulus. Although, it is important to note that differences in testing methodology between studies could explain part of the differences in 505 COD test times. Nonetheless, the current subjects may have been more sensitive to the BHT and even to the 6 min rest following a dynamic warm-up (i.e., the CC). This could have led to the general reduction in 505 COD test times post-CA for both analyzed conditions. Furthermore, it should also be noted that improvements in the 505 COD speed test following the BHT could be due to the placebo effect, whereby the act of the intervention led to performance enhancement [56]. However, given the results of this study and how they support previous research [17,18], it is likely the placebo effect was not an overriding factor.

What is notable is that even if 3 sets $\times 5$ repetitions of BHT with $85 \% 1 \mathrm{RM}$ was not significantly different from the CC, it did lead to a faster 505 COD test performance at multiple time points. Especially in college-aged athletes, training time and exposure can be limited [57]. This puts a greater emphasis on training efficiency. The data from this study suggest that the BHT with a load focused on strength could be implemented prior to COD drills and may even led to a potentiation of COD speed. Given that a variety of training drills have been implemented in an attempt to improve COD speed [2-4], it is beneficial for strength and conditioning coaches to know that as long as recovery time is appropriate, heavy BHT could provide an acute positive impact on COD speed. Although, this improvement was similar to that with the CC within the current investigation.

Previous research has suggested that stronger individuals could experience greater PAPE $[12,17,18,20]$. However, results from this study are counter to these previous findings. There were no significant relationships between absolute and relative lower-body strength measured by the 1RM BHT with 505 COD test percent potentiation. In a similar sample of college-aged men and women, Orjalo et al. [11] found no relationships between vertical jump and lateral bound performance with 505 COD test PAPE following a CA of unweighted or weighted lateral bounds. Similar to Orjalo et al. [11], the training background of the subjects in this study may have influenced these 
results. The mean 1RM BHT for the college-aged subjects in this study was $156.26 \pm 64.17 \mathrm{~kg}$, and this compares favorably with that of collegiate male and female athletes $(\sim 150 \mathrm{~kg})$ [58] and resistance-trained individuals $(145.80 \pm 33.51 \mathrm{~kg})$ [59]. However, there were relatively high SDs for the 1RM BHT for both the men $( \pm 55.87 \mathrm{~kg})$ and women $( \pm 39.27 \mathrm{~kg})$ in this study. This would intimate that there was a spread of subjects with higher and lower strength levels in this study. Perhaps, future research should investigate the differences in COD speed percent potentiation and strength between "stronger" and "weaker" groups. Nonetheless, the subjects were also relatively slower in the 505 COD test, with examples provided in this discussion from elite [33] and collegiate [38,39] athletes. The strength of subjects in this study may not have effectively translated to their COD speed to the extent that there would be a superior ability to potentiate within the 505 COD test. This could also be complicated by the complexity of the COD action, despite both the BHT and COD requiring activation of the hip extensors. As even though the BHT could enhance the power output of the hip extensors due to the muscle's contractile history [6], this may not lead to improved movement technique and strategies that are essential for a COD. Indeed, an effective direction change stresses multiple muscles in the lower body, which must generate force to produce effective biomechanics [60]. The combination of these factors could have limited the strength of relationships between absolute and relative strength and 505 COD test percent potentiation.

There are several limitations to this study that should be acknowledged. As noted, the subject population were recreational athletes. Higher-level athletes may respond differently to a CA [19], and the subjects in this study were slower in the 505 COD test compared to elite [33] and collegiate [38,39] athletes. Accordingly, the findings from this study may not apply to elite athletes. Only one strength exercise (BHT) with one load (85\% 1RM) was analyzed in this study. Dello Iacono and Seitz [18] found that a BHT load that optimized peak power was potentially more beneficial for potentiating 20- $\mathrm{m}$ sprint performance in elite soccer players. It is possible that a BHT that optimized peak power could have potentiated the $505 \mathrm{COD}$ test as well, and this requires investigation. Lastly, only one type of COD speed test was analyzed in this study. There are a variety of COD tests that incorporate different movement patterns [61]. Future research should detail whether the BHT could potentiate other COD speed tests featuring cuts made at different angles.

\section{Conclusions}

The current study revealed that 3 sets $\times 5$ repetitions of BHT with $85 \% 1$ RM was able to enhance COD speed as measured by the 505 COD speed test in college-aged, recreationally trained men and women. This occurred at multiple time points from 4 to 16 min post-CA, but the changes in 505 time were not different from a those due to a CC of 6 min rest. Additionally, there were no significant relationships between absolute and relative lower-body strength measured by the 1RM BHT with 505 percent potentiation. Although the data may have been influenced by the training history of the participants, there are useful implications that can be drawn from this analysis of college-aged men and women. To improve training efficiency in college-aged men and women, strength exercises could be positioned before COD drills that feature actions such as those in the 505 COD test. COD speed could also be potentiated as long as the recovery time is appropriate.

Author Contributions: R.G.L. and S.J.C. were involved in study design, data interpretation, and manuscript writing and editing. A.J.O. was involved in data collection, data interpretation, and manuscript writing and editing. All authors have read and agreed to the published version of the manuscript.

Funding: This research project received no external financial assistance.

Acknowledgments: We would like to acknowledge our subjects for their contribution to this study.

Conflicts of Interest: The authors declare no conflict of interest. 


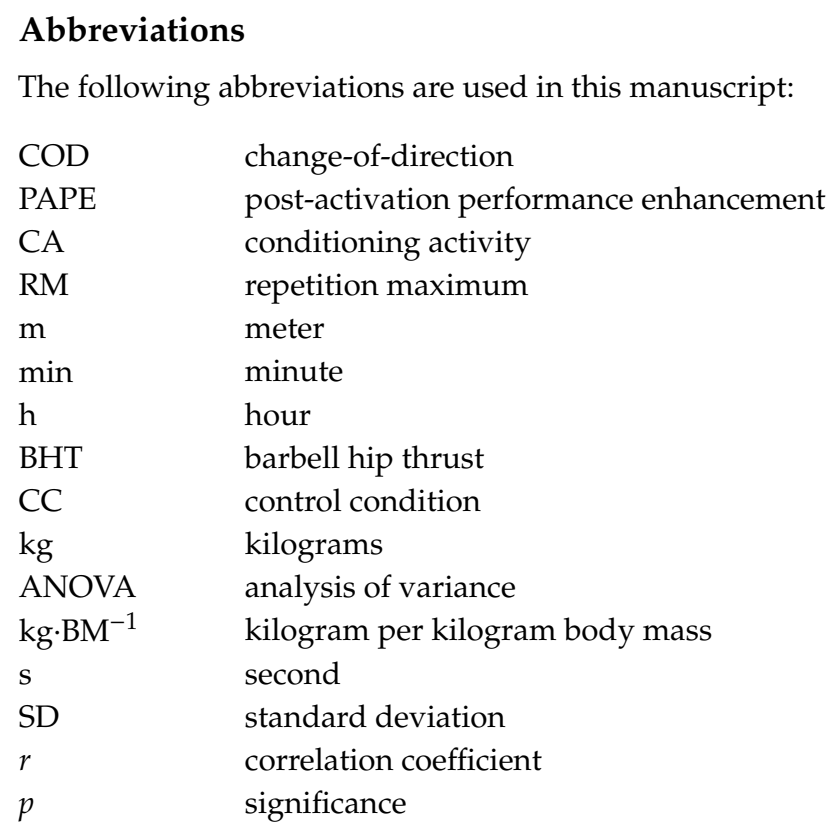

\section{References}

1. Sheppard, J.M.; Young, W.B. Agility literature review: Classifications, training and testing. J. Sports Sci. 2006, 24, 919-932. [CrossRef] [PubMed]

2. Bloomfield, J.; Polman, R.; O'Donoghue, P.; McNaughton, L. Effective speed and agility conditioning methodology for random intermittent dynamic type sports. J. Strength Cond. Res. 2007, 21, 1093-1100.

3. Lockie, R.G.; Schultz, A.B.; Callaghan, S.J.; Jeffriess, M.D. The effects of traditional and enforced stopping speed and agility training on multidirectional speed and athletic performance. J. Strength Cond. Res. 2014, 28, 1538-1551. [CrossRef] [PubMed]

4. Contreras, B.; Vigotsky, A.D.; Schoenfeld, B.J.; Beardsley, C.; McMaster, D.T.; Reyneke, J.H.; Cronin, J.B. Effects of a six-week hip thrust vs. front squat resistance training program on performance in adolescent males: A randomized controlled trial. J. Strength Cond. Res. 2017, 31, 999-1008. [CrossRef] [PubMed]

5. Raya-González, J.; Castillo, D.; Beato, M. The flywheel paradigm in team sports: A soccer approach. Strength Cond. J. 2020, in press. [CrossRef]

6. Tillin, N.A.; Bishop, D. Factors modulating post-activation potentiation and its effect on performance of subsequent explosive activities. Sports Med. 2009, 39, 147-166. [CrossRef]

7. Blazevich, A.J.; Babault, N. Post-activation potentiation versus post-activation performance enhancement in humans: Historical perspective, underlying mechanisms, and current issues. Front. Physiol. 2019, 10, 1359. [CrossRef] [PubMed]

8. Ebben, W.P. Complex training: A brief review. J. Sports Sci. Med. 2002, 1, 42-46.

9. Okuno, N.M.; Tricoli, V.; Silva, S.B.; Bertuzzi, R.; Moreira, A.; Kiss, M.A. Postactivation potentiation on repeated-sprint ability in elite handball players. J. Strength Cond. Res. 2013, 27, 662-668. [CrossRef]

10. Sole, C.J.; Moir, G.L.; Davis, S.E.; Witmer, C.A. Mechanical analysis of the acute effects of a heavy resistance exercise warm-up on agility performance in court-sport athletes. J. Hum. Kinet. 2013, 39, 147-156. [CrossRef]

11. Orjalo, A.J.; Lockie, R.G.; Balfany, K.; Callaghan, S.J. The effects of lateral bounds on post-activation potentiation of change-of-direction speed measured by the 505 test in college-aged men and women. Sports 2020, 8, 71. [CrossRef] [PubMed]

12. Wilson, J.M.; Duncan, N.M.; Marin, P.J.; Brown, L.E.; Loenneke, J.P.; Wilson, S.M.; Jo, E.; Lowery, R.P.; Ugrinowitsch, C. Meta-analysis of postactivation potentiation and power: Effects of conditioning activity, volume, gender, rest periods, and training status. J. Strength Cond. Res. 2013, 27, 854-859. [CrossRef] [PubMed]

13. Zink, A.J.; Perry, A.C.; Robertson, B.L.; Roach, K.E.; Signorile, J.F. Peak power, ground reaction forces, and velocity during the squat exercise performed at different loads. J. Strength Cond. Res. 2006, 20, 658-664. [PubMed] 
14. Morin, J.B.; Bourdin, M.; Edouard, P.; Peyrot, N.; Samozino, P.; Lacour, J.R. Mechanical determinants of 100-m sprint running performance. Eur. J. Appl. Physiol. 2012, 112, 3921-3930. [CrossRef] [PubMed]

15. Simonsen, E.B.; Thomsen, L.; Klausen, K. Activity of mono- and biarticular leg muscles during sprint running. Eur. J. Appl. Physiol. Occup. Phys. 1985, 54, 524-532. [CrossRef] [PubMed]

16. Contreras, B.; Vigotsky, A.D.; Schoenfeld, B.J.; Beardsley, C.; Cronin, J. A comparison of gluteus maximus, biceps femoris, and vastus lateralis electromyographic activity in the back squat and barbell hip thrust exercises. J. Appl. Biomech. 2015, 31, 452-458. [CrossRef] [PubMed]

17. Dello Iacono, A.; Padulo, J.; Seitz, L.D. Loaded hip thrust-based PAP protocol effects on acceleration and sprint performance of handball players. J. Sports Sci. 2018, 36, 1269-1276. [CrossRef] [PubMed]

18. Dello Iacono, A.; Seitz, L.B. Hip thrust-based PAP effects on sprint performance of soccer players: Heavy-loaded versus optimum-power development protocols. J. Sports Sci. 2018, 36, 2375-2382. [CrossRef]

19. Chiu, L.Z.; Fry, A.C.; Weiss, L.W.; Schilling, B.K.; Brown, L.E.; Smith, S.L. Postactivation potentiation response in athletic and recreationally trained individuals. J. Strength Cond. Res. 2003, 17, 671-677.

20. Seitz, L.B.; de Villarreal, E.S.; Haff, G.G. The temporal profile of postactivation potentiation is related to strength level. J. Strength Cond. Res. 2014, 28, 706-715. [CrossRef]

21. Suchomel, T.J.; Sato, K.; DeWeese, B.H.; Ebben, W.P.; Stone, M.H. Potentiation following ballistic and non-ballistic complexes: The effect of strength level. J. Strength Cond. Res. 2016, 30, 1825-1833. [CrossRef] [PubMed]

22. Lockie, R.G.; Orjalo, A.J.; Moreno, M.R. A pilot analysis: Can the Bulgarian split-squat potentiate sprint acceleration in strength-trained men? FU Phys. Ed. Sport 2018, 15, 453-466. [CrossRef]

23. Faul, F.; Erdfelder, E.; Lang, A.G.; Buchner, A. G*Power 3: A flexible statistical power analysis program for the social, behavioral, and biomedical sciences. Behav. Res. Methods 2007, 39, 175-191. [CrossRef] [PubMed]

24. Lockie, R.G.; Davis, D.; Giuliano, L.; Risso, D.V.; Orjalo, F.G.; Moreno, A.J.; Lazar, A. A preliminary case analysis of the post-activation potentiation effects of plyometrics on sprint performance in women. Sport Sci. Rev. 2016, 25, 300-319. [CrossRef]

25. Lockie, R.; Lazar, G.; Risso, A.; Giuliano, D.; Liu, T.M.; Stage, A.A.; Birmingham-Babauta, S.A.; Stokes, J.; Davis, D.L.; Moreno, M.R.; et al. Limited post-activation potentiation effects provided by the walking lunge on sprint acceleration: A preliminary analysis. TOSSJ 2017, 10, 97-106. [CrossRef]

26. Barber, O.R.; Thomas, C.; Jones, P.A.; McMahon, J.J.; Comfort, P. Reliability of the 505 change-of-direction test in netball players. Int. J. Sports Physiol. Perform. 2016, 11, 377-380. [CrossRef]

27. Crewther, B.T.; Kilduff, L.P.; Cook, C.J.; Middleton, M.K.; Bunce, P.J.; Yang, G.Z. The acute potentiating effects of back squats on athlete performance. J. Strength Cond. Res. 2011, 25, 3319-3325. [CrossRef]

28. Turner, A.P.; Bellhouse, S.; Kilduff, L.P.; Russell, M. Postactivation potentiation of sprint acceleration performance using plyometric exercise. J. Strength Cond. Res. 2015, 29, 343-350. [CrossRef]

29. Whelan, N.; O'Regan, C.; Harrison, A.J. Resisted sprints do not acutely enhance sprinting performance. J. Strength Cond. Res. 2014, 28, 1858-1866. [CrossRef]

30. Contreras, B.; Cronin, J.; Schoenfeld, B. Barbell hip thrust. Strength Cond. J. 2011, 33, 58-61. [CrossRef]

31. Lockie, R.G.; Moreno, M.R.; Lazar, A.; Risso, F.G.; Tomita, T.M.; Stage, A.A.; Birmingham-Babauta, S.A.; Torne, I.A.; Stokes, J.J.; Giuliano, D.V.; et al. The 1-repetition maximum mechanics of a high-handle hexagonal bar deadlift compared to a conventional deadlift as measured by a linear position transducer. J. Strength Cond. Res. 2018, 32, 150-161. [CrossRef] [PubMed]

32. Lockie, R.G.; Moreno, M.R.; Orjalo, A.J.; Lazar, A.; Liu, T.M.; Stage, A.A.; Birmingham-Babauta, S.A.; Stokes, J.J.; Giuliano, D.V.; Risso, F.G.; et al. The relationships between height, arm length, and leg length on the mechanics of the conventional and high-handle hexagonal bar deadlift. J. Strength Cond. Res. 2018, 32, 3011-3019. [CrossRef] [PubMed]

33. Delaney, J.A.; Scott, T.J.; Ballard, D.A.; Duthie, G.M.; Hickmans, J.A.; Lockie, R.G.; Dascombe, B.J. Contributing factors to change-of-direction ability in professional rugby league players. J. Strength Cond. Res. 2015, 29, 2688-2696. [CrossRef] [PubMed]

34. Lockie, R.G.; Callaghan, S.J.; Jeffriess, M.D. Analysis of specific speed testing for cricketers. J. Strength Cond. Res. 2013, 27, 2981-2988. [CrossRef]

35. Lockie, R.G.; Jalilvand, F.; Orjalo, A.J.; Giuliano, D.V.; Moreno, M.R.; Wright, G.A. A methodological report: Adapting the 505 change-of-direction speed test specific to American football. J. Strength Cond. Res. 2017, 31, 539-547. [CrossRef] 
36. Lockie, R.G.; Post, B.K.; Dawes, J.J. Physical qualities pertaining to shorter and longer change-of-direction speed test performance in men and women. Sports 2019, 7, 45. [CrossRef]

37. Post, B.K.; Dawes, J.J.; Lockie, R.G. Relationships between tests of strength, power, and speed and the 75-yard pursuit run. J. Strength Cond. Res. 2019, in press. [CrossRef]

38. Lockie, R.G.; Dawes, J.J.; Jones, M.T. Relationships between linear speed and lower-body power with change-of-direction speed in National Collegiate Athletic Association Divisions I and II women soccer athletes. Sports 2018, 6, 30. [CrossRef]

39. Lockie, R.G.; Moreno, M.R.; Orjalo, A.J.; Stage, A.A.; Liu, T.M.; Birmingham-Babauta, S.A.; Hurley, J.M.; Torne, I.A.; Beiley, M.D.; Risso, F.G.; et al. Repeated-sprint ability in Division I collegiate male soccer players: Positional differences and relationships with performance tests. J. Strength Cond. Res. 2019, 33, 1362-1370. [CrossRef]

40. Lockie, R.G.; Callaghan, S.J.; Orjalo, A.J.; Moreno, M.R. Loading range for the development of peak power in the close-grip bench press versus the traditional bench press. Sports 2018, 6, 97. [CrossRef]

41. Jeffriess, M.D.; Schultz, A.B.; McGann, T.S.; Callaghan, S.J.; Lockie, R.G. Effects of preventative ankle taping on planned change-of-direction and reactive agility performance and ankle muscle activity in basketballers. J. Sports Sci. Med. 2015, 14, 864-876. [PubMed]

42. Callaghan, S.J.; Lockie, R.G.; Andrews, W.A.; Chipchase, R.F.; Nimphius, S. The relationship between inertial measurement unit-derived 'force signatures' and ground reaction forces during cricket pace bowling. Sport Biomech. 2020, 19, 307-321. [CrossRef] [PubMed]

43. Cormack, S.J.; Newton, R.U.; McGuigan, M.R.; Doyle, T.L. Reliability of measures obtained during single and repeated countermovement jumps. Int. J. Sports Physiol. Perform. 2008, 3, 131-144. [CrossRef] [PubMed]

44. Standing, R.J.; Maulder, P.S. The biomechanics of standing start and initial acceleration: Reliability of the key determining kinematics. J. Sports Sci. Med. 2017, 16, 154-162.

45. Comyns, T.M.; Harrison, A.J.; Hennessy, L.K.; Jensen, R.L. The optimal complex training rest interval for athletes from anaerobic sports. J. Strength Cond. Res. 2006, 20, 471-476.

46. Bevan, H.R.; Cunningham, D.J.; Tooley, E.P.; Owen, N.J.; Cook, C.J.; Kilduff, L.P. Influence of postactivation potentiation on sprinting performance in professional rugby players. J. Strength Cond. Res. 2010, 24, 701-705. [CrossRef]

47. Lockie, R.G.; Dawes, J.J.; Orr, R.M.; Stierli, M.; Dulla, J.M.; Orjalo, A.J. An analysis of the effects of sex and age on upper- and lower-body power for law enforcement agency recruits prior to academy training. J. Strength Cond. Res. 2018, 32, 1968-1974. [CrossRef]

48. Lindle, R.S.; Metter, E.J.; Lynch, N.A.; Fleg, J.L.; Fozard, J.L.; Tobin, J.; Roy, T.A.; Hurley, B.F. Age and gender comparisons of muscle strength in 654 women and men aged 20-93 yr. J. Appl. Physiol. 1997, 83, 1581-1587. [CrossRef]

49. Dillman, C.F.R.; Stevens, E.M. Sex in the media, sex on the mind: Linking television use, sexual permissiveness, and sexual concept accessibility in memory. Sex Cult. 2018, 22, 22-38. [CrossRef]

50. Lockie, R.G.; Balfany, K.; Denamur, J.K.; Moreno, M.R. A preliminary analysis of relationships between a 1RM hexagonal bar load and peak power with the tactical task of a body drag. J. Hum. Kinet. 2019, 68, 157-166. [CrossRef]

51. Lockie, R.G.; Dawes, J.J.; Balfany, K.; Gonzales, C.E.; Beitzel, M.M.; Dulla, J.M.; Orr, R.M. Physical fitness characteristics that relate to Work Sample Test Battery performance in law enforcement recruits. Int. J. Environ. Res. Public Health 2018, 15, 2477. [CrossRef] [PubMed]

52. Lockie, R.G.; Ruvalcaba, T.R.; Stierli, M.; Dulla, J.M.; Dawes, J.J.; Orr, R.M. Waist circumference and waist-to-hip ratio in law enforcement agency recruits: Relationship to performance in physical fitness tests. J. Strength Cond. Res. 2020, 34, 1666-1675. [CrossRef]

53. Mackey, S.; Chaarani, B.; Kan, K.J.; Spechler, P.A.; Orr, C.; Banaschewski, T.; Barker, G.; Bokde, A.L.W.; Bromberg, U.; Buchel, C.; et al. Brain regions related to impulsivity mediate the effects of early adversity on antisocial behavior. Biol. Psychiatry 2017, 82, 275-282. [CrossRef] [PubMed]

54. Lewton, M.; Ashwin, C.; Brosnan, M. Syllogistic reasoning reveals reduced bias in people with higher autistic-like traits from the general population. Autism 2019, 23, 1311-1321. [CrossRef] [PubMed]

55. Hopkins, W.G. A Scale of Magnitude for Effect Statistics. 2002. Available online: www.sportsci.org/resource/ stats/index.html (accessed on 11 November 2019). 
56. Beedie, C.J.; Foad, A.J. The placebo effect in sports performance: A brief review. Sports Med. 2009, 39, 313-329. [CrossRef] [PubMed]

57. Lockie, R.G.; Birminagham-Babauta, S.A.; Stokes, J.J.; Liu, T.M.; Risso, F.G.; Lazar, A.; Giuliano, D.V.; Orjalo, A.J.; Moreno, M.R.; Stage, A.A.; et al. An analysis of collegiate club-sport female lacrosse players: Sport-specific field test performance and the influence of stick carry on speed. Int. J. Exerc. Sci. 2018, 11, 269-280.

58. Jarvis, P.; Cassone, N.; Turner, A.; Chavda, S.; Edwards, M.; Bishop, C. Heavy barbell hip thrusts do not effect sprint performance: An 8-week randomized controlled study. J. Strength Cond. Res. 2019, 33, S78-S84. [CrossRef] [PubMed]

59. Zweifel, M.; Vigotsky, A.; Contreras, B.; Njororai, S.W. Effects of 6-week squat, deadlift, or hip thrust training program on speed, power, agility, and strength in experienced lifters: A pilot study. J. Trainol. 2017, 6, 13-17. [CrossRef]

60. Neptune, R.R.; Wright, I.C.; van den Bogert, A.J. Muscle coordination and function during cutting movements. Med. Sci. Sports Exerc. 1999, 31, 294-302. [CrossRef]

61. Lockie, R.G. Testing, assessment, and monitoring of agility and quickness. Hum. Kinet. 2019, 2, 77-98.

Publisher's Note: MDPI stays neutral with regard to jurisdictional claims in published maps and institutional affiliations.

(C) 2020 by the authors. Licensee MDPI, Basel, Switzerland. This article is an open access article distributed under the terms and conditions of the Creative Commons Attribution (CC BY) license (http://creativecommons.org/licenses/by/4.0/). 